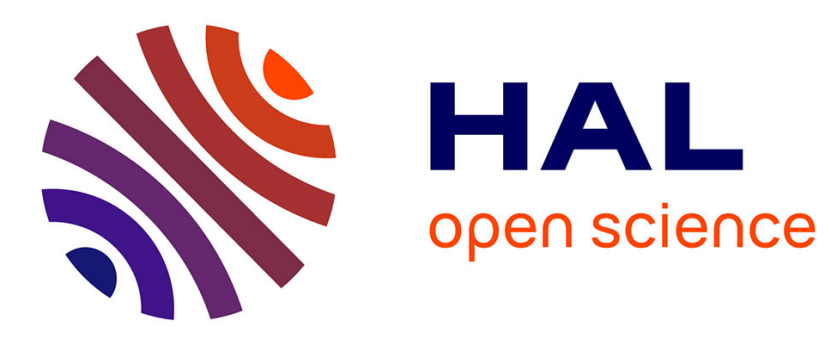

\title{
Tube Drawing Process Modelling By A Finite Element Analysis
}

Muriel Palengat, Olivier Guiraud, Christophe Millet, Grégory Chagnon, Denis Favier

\section{- To cite this version:}

Muriel Palengat, Olivier Guiraud, Christophe Millet, Grégory Chagnon, Denis Favier. Tube Drawing Process Modelling By A Finite Element Analysis. Materials \& Processes for Medical Devices Conference, Sep 2007, Palm Desert, CA, United States. pp.65-72. hal-01978976

\section{HAL Id: hal-01978976 https://hal.science/hal-01978976}

Submitted on 12 Jan 2019

HAL is a multi-disciplinary open access archive for the deposit and dissemination of scientific research documents, whether they are published or not. The documents may come from teaching and research institutions in France or abroad, or from public or private research centers.
L'archive ouverte pluridisciplinaire HAL, est destinée au dépôt et à la diffusion de documents scientifiques de niveau recherche, publiés ou non, émanant des établissements d'enseignement et de recherche français ou étrangers, des laboratoires publics ou privés. 


\title{
Tube Drawing Process Modelling By A Finite Element Analysis
}

\author{
M. Palengat, O. Guiraud, C.Millet \\ Minitubes, Grenoble, France \\ G. Chagnon, D. Favier \\ Universités de Grenoble, Grenoble, France
}

\begin{abstract}
Drawing process is used in manufacturing thin-walled tubes, while reducing progressively their wall thickness and their inner and outer diameters. In this paper a stainless steel 316LVM is studied with one drawing process: hollow sinking. This study gets into different issues including elastoplastic behaviour, thermomechanical coupling, contacts, friction and numerical convergence. Experimental drawings are realized on a testing bench where forces, dimensional data and temperature are recorded. In a first approach, tensile tests lead us to use an elastoplastic constitutive equation with an isotropic hardening law. In simulations, an axisymetric steadystate thermomechanical model is used. Numerical results are compared with experimental results. Finally, in spite of some defaults, this study shows that finite element modelling is able to foresee accurately the thermomechanical behaviour of a tube during a drawing process. A better understanding and modelling of the thermomechanical behaviour of materials will improve the FEM simulation results.
\end{abstract}

\section{Introduction}

Thin-walled tubes are manufactured with the tube drawing process, reducing progressively inner and outer diameters together with wall thickness. In most cases, industries develop empirically their production. As it induces many experiments, this method costs a lot of time and energy. Numerical simulation would be an alternative solution which would require firstly to characterize the material with simple mechanical tests available for tube geometries; then numerical simulation would allow to test the feasibility of drawing passes and to give an optimized range of production. This would reduce the number of experimental tests and then the cost of development. Such an approach is explored in this paper for hollow sinking drawing of stainless steel tubes.

Few works exist on tube drawing process but different studies have already been realized to optimize tools' geometries [1] and observe stresses and strains with several drawing processes [2, 3, 4]. Karnezis and Farrugia [5] developed an optimization procedure based on the Cockcroft-Latham workability failure criterion. None of these works justify the value of their friction coefficient. Lazzarato et al. [7] carried out an inverse analysis on the basis of mechanical tests. They performed a new upsetting sliding test recreating the wire drawing process conditions in order to identify the Coulomb's friction coefficient.

The aim of the present study is to model tube drawing with a thermomechanical finite element (FE) analysis. This paper focuses on cold drawing without inner plug (hollow sinking) of stainless steel 316LVM (ASTM F138) tubes of small diameters (typically of the order of 1 to $6 \mathrm{~mm}$ ).

First, hollow sinking tests are performed on draw-benches with several sensors, i.e. load cells, thermocouples and pyrometer. Drawing forces and inner and outer temperatures are measured during the drawing process for tube of initial different diameters and thicknesses.

Subsequently, a thermomechanical model is used. Accurate modeling results imply to have a deep knowledge of parameters that affect the process as tools and tubes geometries and of materials behaviour. The main difficulties are due to large deformations and complex contact conditions which must be well characterized and which involve numerical convergence problems.

In a first part, drawing experiments performed on drawbenches are described, the second part details the modelling hypotheses including constitutive equations to describe the materials mechanical behaviour. In a third part, experimental measurements and results predicted by the FE model are compared and discussed.

\section{Drawing Experiments}

Tube drawings were realized on a testing bench, presented in Fig. 1 with a stainless steel (316LVM). A simulation of this process is realized further and compared with these experimental data. 


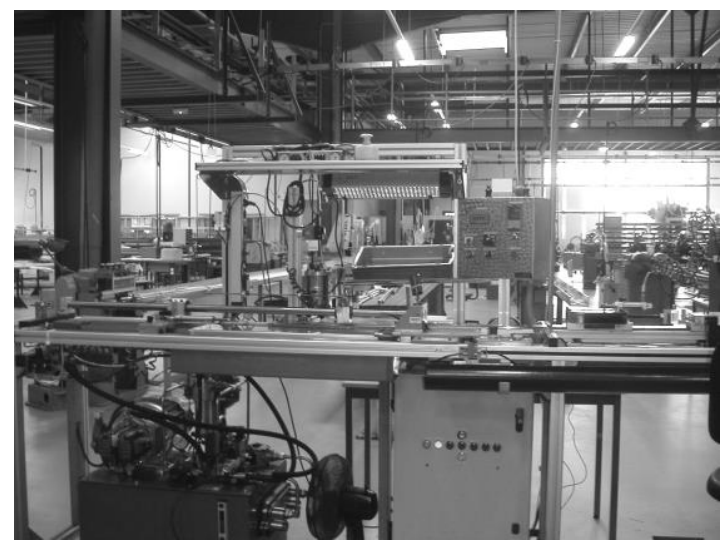

Figure 1: Drawbench.

\section{Hollow Sinking:}

Measurements were done during hollow sinking tests. The process is presented in Fig. 2. A tube is introduced in a die which has a diameter smaller than the tube outer diameter. The drawing speed is $14.3 \mathrm{~m} / \mathrm{min}$. A load cell takes place on the drawing device to record the drawing force. Moreover, two thermal sensors are used. A thermocouple, placed inside the tube records the evolution of the temperature of a point on the inner surface of the tube during the process. A pyrometer is placed after the die exit, and records the time evolution of the temperature at a spatial point distant of $8 \mathrm{~cm}$ from the die exit.

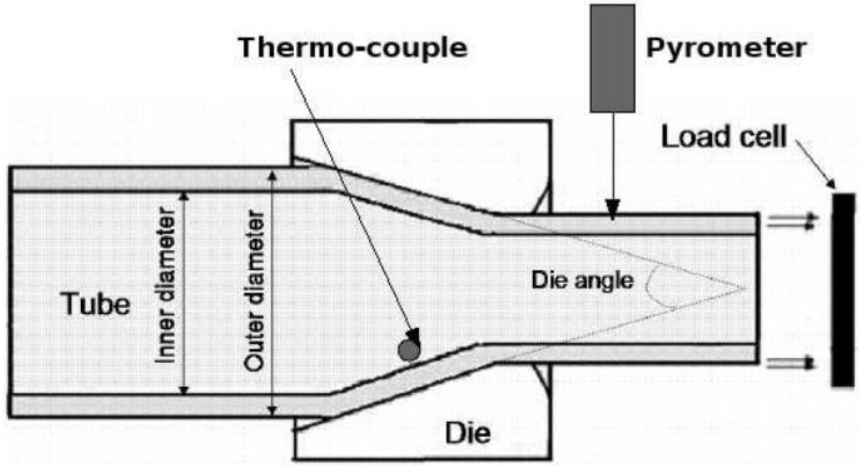

\section{Figure 2: Hollow sinking}

In the first test the outer and inner diameters of the tube before drawing are equal to $6.64 \mathrm{~mm}$ and $5.8 \mathrm{~mm}$, respectively. Two other tests were carried out with different tube diameters (8.15 $\mathrm{x} 7 \mathrm{~mm}^{2}$ and $4.06 \times 3.5 \mathrm{~mm}^{2}$ ). Tungsten carbide conical dies were used. Details of experiments data (initial tube and die geometries) are listed in table 1.

The time-drawing force curve (Fig. 3) is composed of three parts. In a first stage, the tube enters in the die and the drawing force increases quickly. During the second stage, the drawing process reaches a steady state where the force is practically constant. In the third stage, the drawing force decreases when the tube exits the die. In the following, we will consider only the steady state. Besides the tube extremities are not used for industrial applications as they do not have the same material and geometrical properties. In fact, they are only used to fix the tube.

Table 1: Experimental measurements for hollow sinking before drawing.

\begin{tabular}{ccccc}
\hline \multirow{E}{*}{} & $\begin{array}{c}\text { Initial Tube } \\
(\boldsymbol{\Phi e x t} \times \mathbf{\Phi} \text { int }) \\
\mathbf{m m}\end{array}$ & $\begin{array}{c}\text { Die } \\
\text { Angle }\end{array}$ & $\begin{array}{c}\text { Die } \\
\text { Diameter } \\
\mathbf{m m}\end{array}$ & $\begin{array}{c}\text { Die } \\
\text { bearing } \\
\mathbf{m m}\end{array}$ \\
\hline 1 & $8.1 \times 7.0$ & 25 & 6.7 & $17 \%$ \\
2 & $6.6 \times 5.8$ & 25 & 5.2 & $17 \%$ \\
3 & $5.2 \times 4.5$ & 25 & 4.1 & $17 \%$ \\
\hline
\end{tabular}

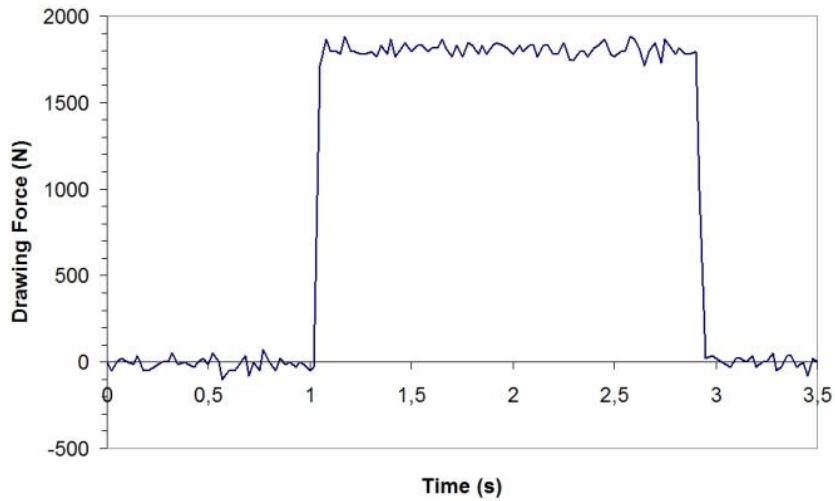

Figure 3: Variation of the experimental drawing force

Drawing forces during the steady state and final dimensions were recorded and are summarized in table 2 .

Table 2: Experimental measurements for hollow sinking after drawing.

\begin{tabular}{|c|c|c|c|c|}
\hline שू & $\begin{array}{c}\text { Final Tube } \\
(\Phi e x t \times \Phi \text { int }) \\
\text { mm }\end{array}$ & $\begin{array}{c}\text { Drawing } \\
\text { force } \\
\mathbf{N} \\
\end{array}$ & $\begin{array}{c}\text { Temperature } \\
\text { Inner } \\
\text { surface }{ }^{\circ} \mathrm{C}\end{array}$ & $\begin{array}{c}\text { Temperature } \\
\text { Outer } \\
\text { surface }{ }^{\circ} \mathrm{C}\end{array}$ \\
\hline 1 & $6.6 \times 5.8$ & 2870 & & \\
\hline 2 & $5.2 \times 4.5$ & 1806 & 60 & 117 \\
\hline 3 & $4.1 \times 3.5$ & & & 102 \\
\hline
\end{tabular}

\section{Numerical Simulation}

Hypothesis:

As geometries and loading conditions are axially symmetric, an axisymmetric model is used. The steady-state condition is the dominating phase in tube drawing. Then, only the steady 
state and a part of the total tube length are considered in a first approach.

Tube cold drawing implies large plastic deformation. Inelastic phenomena and friction generate heat. In a first approach it is assumed that the materials behaviours are temperature independent. Thus the material model does not take into account temperature. In the range of temperature variation, the material properties do not vary more than $1 \%$.

Besides, during drawing, strain rates are of the order of 10 to $100 \mathrm{~s}^{-1}$. However, the tests are at room temperature $\mathrm{T}(300 \mathrm{~K})$, and the melting point $\mathrm{Tf}$ of the studied alloys are higher than $1500 \mathrm{~K}$; with regard to the ratio $\mathrm{T} / \mathrm{Tf}$ lower than 0.2 , it is assumed that the materials behaviours are considered as insensitive to strain rates in a first approach.

Lubricants affect the drawing but lubrication is supposed homogeneous and constant during the process. Thus variations in lubrication are not taken into account and only a constant Coulomb coefficient is used to model friction.

Finally, as the time of drawing is relatively short, the model is considered adiabatic and the conduction at the tube-die contact is supposed to be negligible.

Then, an elastoplastic constitutive equation is applied to model the materials behaviour. In order to characterize the plastic behaviour, simple tests are performed.

\section{Physical Modelling:}

\section{Material Behaviour}

The studied material, a stainless steel (316LVM), has a large ductility and can be cold formed.

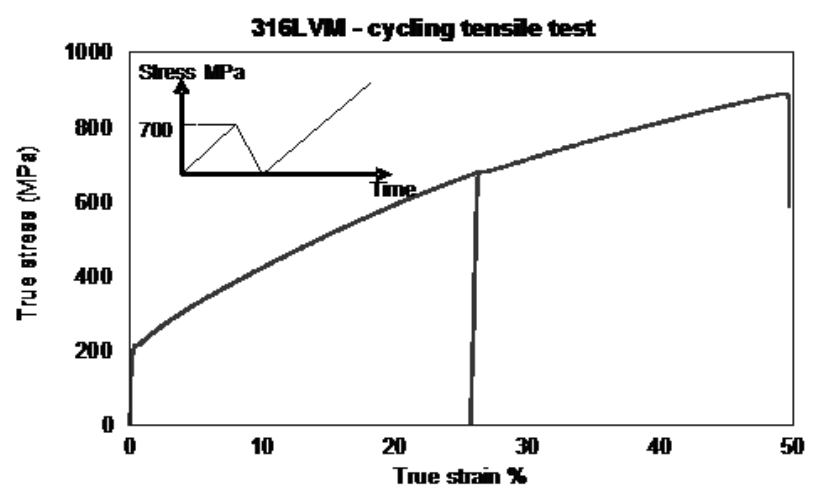

Figure 4: Stress-strain curve of the 316LVM cycling test.

Only tensile tests are available for thin-wall tubes. They are easy to realize, but they are not sufficient to understand the material behaviour during drawing. Indeed tensile tests permit to observe only one strain direction and are not sufficient to correctly define the hardening law.

These tests lead up to apply in a first approach an elastoplastic constitutive equation with an isotropic hardening law. The elastic behaviour is described by Young's modulus and Poisson's ratio. The true strain-true stress curve describes the plastic behaviour (Fig. 4).

Thermal properties are listed in table 3. They are valid for temperatures ranging between $20^{\circ} \mathrm{C}$ and $100^{\circ} \mathrm{C}$. Friction coefficient is equal to 0.1 , proposed by Lazzarato et al. [7]. Heat generated by friction is equally shared between the tube and the die.

\section{Table 3: Thermal properties}

\begin{tabular}{lcc}
\hline Material & 316LVM & WC \\
\hline Thermal conductivity $\left(\mathrm{W} \cdot \mathrm{m}^{-1} \cdot \mathrm{K}^{-1}\right)$ & 15 & 100 \\
\hline Density $\left(\mathrm{Kg} \cdot \mathrm{m}^{-3}\right)$ & 7800 & 3520 \\
\hline Specific heat $\left(\mathrm{N} \cdot \mathrm{m} \cdot \mathrm{kg}^{-1} \cdot \mathrm{K}^{-1}\right)$ & 500 & 500 \\
\hline Inelastic heat fraction & 0.9 & $\emptyset$ \\
\hline
\end{tabular}

\section{Tools Behaviour}

Dies are in tungstene carbide (WC). They are assumed to deform elastically because of their high elastic limit. Moreover no plastic deformation has ever been observed on tools after a drawing. Their elastic properties are listed in table 4.

Table 4: Elastic properties of the tube and tools materials.

\begin{tabular}{lcc}
\hline Material & 316LVM & WC \\
\hline Young's modulus $(\mathrm{GPa})$ & 210 & 650 \\
\hline Poisson's coefficient & 0.3 & 0.2 \\
\hline
\end{tabular}

\section{Friction}

The friction coefficient depends on a lot of parameters (materials, lubricants, surfaces...) and it is difficult to determine it. In metal forming, the Coulomb model accounts for the effects of friction. A shear stress limit could have been applied if there were large normal stresses. This model does not take into account the fluctuation of lubrication. The Coulomb coefficient has been chosen in the literature [7].

Numerical Modelling:

Load

Boundary conditions are shown in Fig. 5. They are the same as in experiments. Dies are fixed. Tube is drawn with a constant speed. In fact the speed has no influence here, as the model is quasi-static and the friction and material behaviour are rate independent (cf. $§$ Hypotheses). 
Temperature of the system die/tube is initially fixed at room temperature. Thermal flow on external surfaces of the system is null, as the system is considered adiabatic.

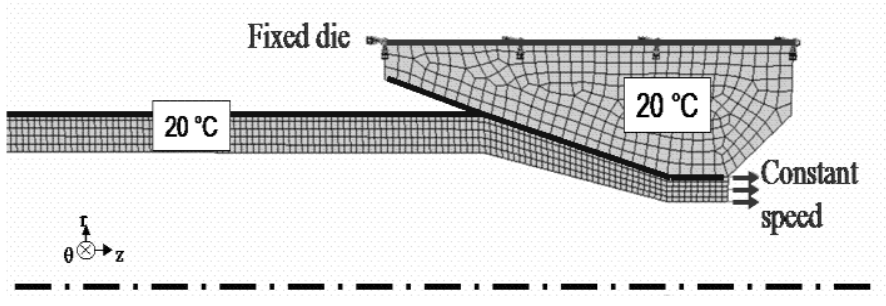

Figure 5: Boundary conditions of the drawing process model.

\section{Meshing}

Triangular elements are very versatile and convenient to mesh complex shapes. However, quadrilateral elements are able to provide an accurate solution at less cost. Quadrilateral elements have a better convergence than triangles but are less accurate if they are initially distorted (Abaqus 2006). In our case they are appropriate to mesh all instances except the dies. Consequently, tubes and plugs are meshed with 8-node axisymmetric thermally coupled quadrilateral, biquadratic in displacement and bilinear in temperature (CAX8T).

\section{Comparison Drawing Experiments - Simulation}

Observations of the simulation results

Qualitatively, the same behaviours as in experimental process are noticed. First, in sinking, the tube peels off from the die, the centripetal flow continues a bit. The detachment is viewed in Fig 6. It implies that sunken tube diameters are slightly lower than die diameters. The detachment is of the order of some hundredths of a millimetre.

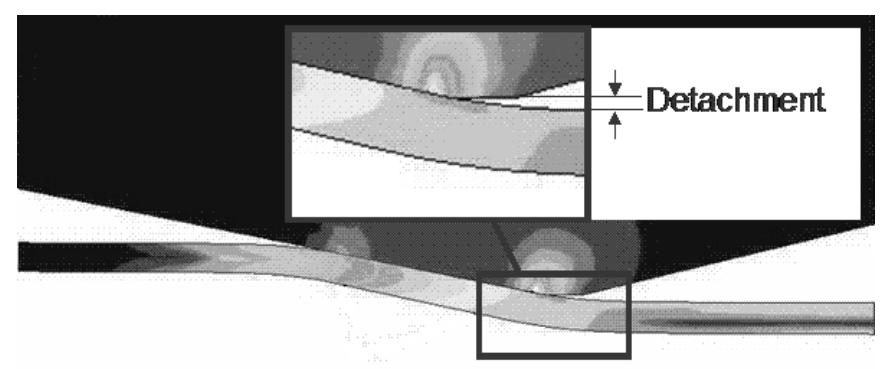

Figure 6: Observations of a finite element simulation of a hollow sinking tube process.

Figure 7 presents the time evolution of the drawing force during a hollow sinking simulation. It can be observed that, after a rapid increase at the beginning, the drawing force stays constant during the process. The drawing force is recorded during the steady state.

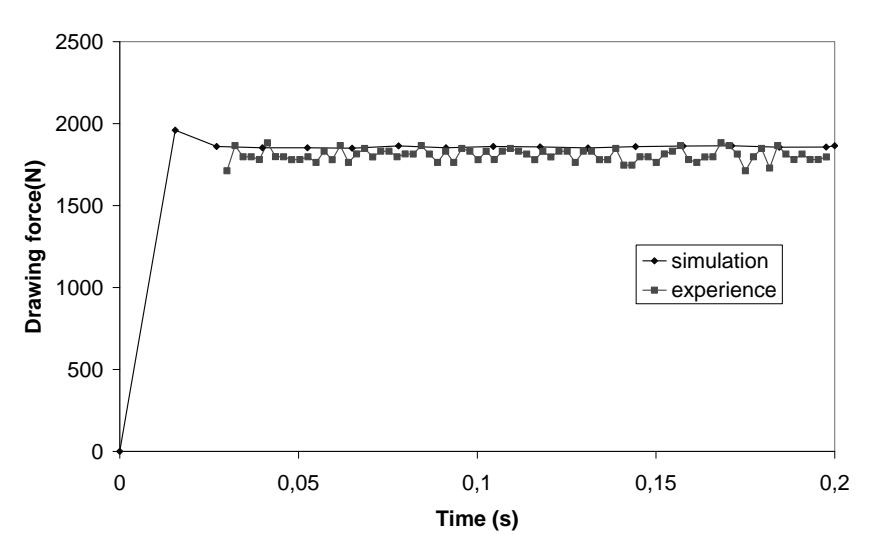

Figure 7: Evolution of the drawing force according to time for a hollow sinking test.

Moreover, two compression points on the die can also be seen in Fig. 6. They take place where the tube changes direction and creates stress in the die. Damages are also observed here on real dies on which wear rings are generated during drawing process. Figure 8 shows a wear ring on a wire drawing diamond die.

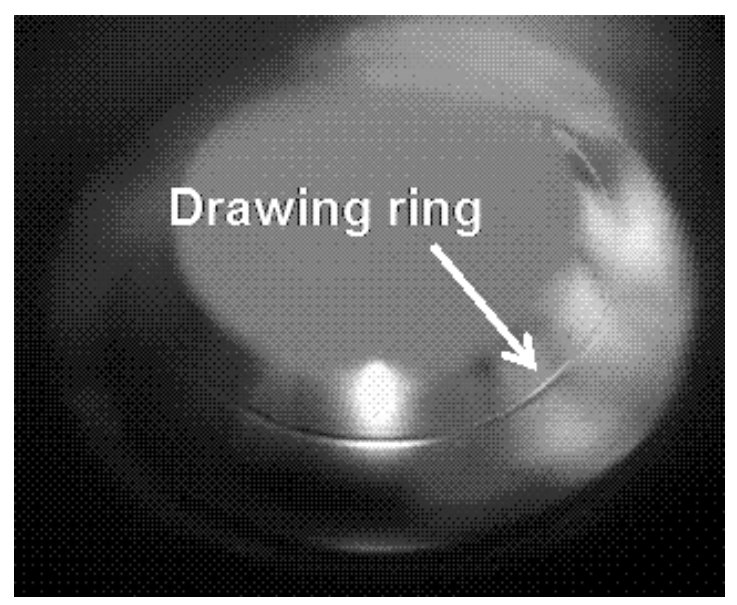

Figure 8: Drawing ring on a die (ESTEVES-DWD).

Then Fig. 9 illustrates the distribution of temperature in the tube and the die. The temperature strongly increases on the outer surface of the tube because of the heat generated by friction. In the rest of the tube, the increase is lower and is due to the inelastic heat generation. Far from the die exit (it cannot be seen in this figure) temperature homogenizes in the thickness. Besides it can be noted that the die temperature is very high $\left(>1000{ }^{\circ} \mathrm{C}\right)$. 


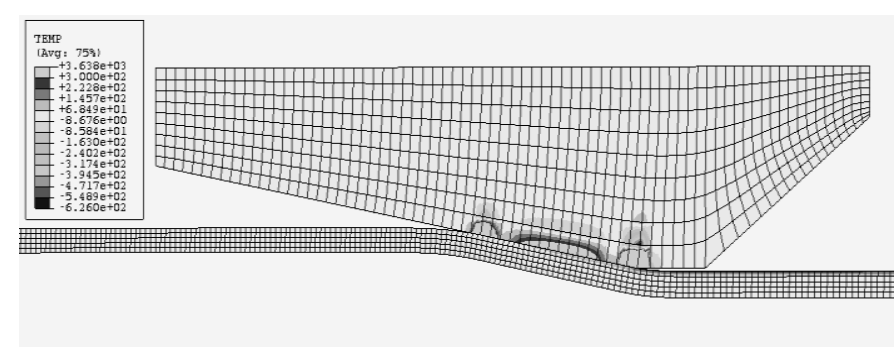

Figure 9: Observations of temperature during the hollow sinking process.

Finally, in hollow sinking, the tube is not constrained inside, so the thickness increases to make the reduction of diameters easier.

Thermomechanical Modelling

As shown in Fig 7, there is a good agreement between experiment and simulation. Indeed, the numerical and experimental drawing force necessary to pull the tube through the die are quite similar for the steady state studied. To date, even if some experimental values miss, a first approach could be carried out with available data presented in table 4. For each drawing, initial tube diameters are reported. The inner and outer temperatures as well as drawing forces are obtained in the simulations. Then the data predicted by the FE model and the experimental measurements are confronted and the results are conclusive.

Table 5: Numerical and experimental results.

\begin{tabular}{ccccc}
\cline { 2 - 5 } & $\begin{array}{c}\mathbf{\Phi e x t} \times \boldsymbol{\Phi} \text { int } \\
\mathbf{m m}\end{array}$ & $\begin{array}{c}\text { Text } \\
\left({ }^{\circ} \mathbf{C}\right)\end{array}$ & $\begin{array}{c}\text { Tint } \\
\left({ }^{\circ} \mathbf{C}\right)\end{array}$ & $\begin{array}{c}\text { Drawing } \\
\text { Force(N) }\end{array}$ \\
\hline Experimental & $6.6 \times 5.8$ & & & 2870 \\
Numerical & $6.5 \times 5.3$ & & & 2677 \\
\hline Experimental & $5.2 \times 4.5$ & 117 & 60 & 1806 \\
Numerical & $5.1 \times 4.2$ & 118 & 68 & 1885 \\
\hline Experimental & $4.1 \times 3.5$ & 102 & & \\
Numerical & $4.0 \times 3.2$ & 101 & & \\
\hline
\end{tabular}

Indeed it appears that the maximum difference between the experimental and numerical drawing forces is lower than $7 \%$. For inner temperatures, relative error between model and tests is $13 \%$. To finish, relative error for outer temperatures is lower than $1.2 \%$.

These results are encouraging for the continuance of the coupled thermomechanical studies. Moreover model can be improved afterwards.

\section{Conclusions}

First, forces and thermal data are observed and results were encouraging. Modelling allows to assess lots of phenomena and to be interested in data, difficult to observe experimentally.

An elastoplastic constitutive equation with an isotropic hardening is applied with a Coulomb's friction coefficient of 0.1 . Hollow sinking FE model is in good agreement with experimental measurements.

However, some inaccuracies appear. It may be due to the determination of the materials plasticity model. The stressstrain curves obtained by tensile tests are limited and do not account entirely for the materials behaviour. Indeed during the drawing, the material undergoes two strains: a longitudinal tension and a radial compression. Then, a better experimental test must be used. An adapted test would be a tensile test with radial compression at the same time but its realization is difficult. An equivalent of these two strains is the shearing. It seems to be easier to realize and is currently done to define better the material behaviour. Moreover, as cycling tests are not available in tensile tests, cyclic shear tests will allow to determine the hardening type. Indeed elastic springback will be observed and the influence of kinematic hardening will be quantified. Improving the determination of the hardening type will improve the prediction of the final dimensions of the final tube.

In the first approach of this paper, three parameters appear to be very important for the modelling. The first, friction coefficient is the most important; it has a great influence on the drawing force, but also on external temperature of tube and die. The second is the inelastic heat fraction. This coefficient has an influence on the temperature generated by the plastic deformation of material during drawing. Finally, the third is the heat distributed to tube fraction. This coefficient makes it possible to distribute the heat generated by friction to various surfaces in contact.

For this study two hypotheses were assumed. First, losses due to convection after die are supposed to be negligible. Studies are in progress in order to check this assumption. Secondly, contact conduction between die and tube is also considered negligible. Indeed, the time of drawing is too short and thus the time of contact between die and tube is very small $(<1 \mathrm{~s})$. However, it is necessary to conform these hypotheses because the difference of temperature between die and tube is large and external temperature of the tube at the end of the process is higher than the one at the beginning. Experimental data go in this way.

\section{References}

1. K. Um, and D. N. Lec, An upper bound solution of tube drawing, J. Mater. Process. Technol. 63, 43-48 (1997).

2. F. O. Neves et al., Numerical and experimental analysis of tube drawing with fixed plug, J. of the Braz. Soc. Of Mech. 
Sci \& Eng. October-december 2005, vol. XXVII, No. A, pp. 426-431.

3. K. Yoshida, H. Furuya, Mandrel drawing and plug drawing of shape-memory-alloy fine tubes used in catheters and stents, J. Mater. Process. Technol. 153-154 (2004) 145150 .

4. K. Yoshida, M. Watanabe and H. Ishikawa, Drawing of Ni-Ti SMA fine tubes used in medical tests, J. Mater. Process. Technol. 118 (2001) 251-255.

5. P. Karnezis et D.C.J. Farrugia, Study of cold tube drawing by finite-element modelling, J. of Mat. Processing Technol., 80-81 (1998) 690-694.

6. Abaqus v. 6.6 "21.1.1 Solid (continuum) elements" in Abaqus Analysis user's manual, 2006.

7. L. Lazzarato, L. Dubar, A. Dubois, P. Ravassard and J. Oudin, Identification of Coulomb's friction coefficient in real contact conditions applied to a wire drawing process, Wear, 211 (1997) 54-63. 